DOI: $10.12957 /$ teias.\%Y.50738

\title{
“ESSE NEGÓCIO DE PADRÃO É MUITO RETRÓGRADO”: o corpo como superfície de inúmeras interpretações
}

\author{
Julia da Fonseca Lopes \\ Dinah Quesada Beck
}

\section{Resumo}

À luz dos Estudos Culturais e dos Estudos de Gênero, ambos em suas vertentes pós-estruturalistas de análise, este artigo reúne alguns dados de pesquisa com os quais buscamos dialogar no intuito de identificar quais representações estão sendo construídas sobre corpo e gênero em relação às práticas de sociabilidade virtual na mídia social Instagram. Metodologicamente, caracteriza-se como um estudo etnográfico virtual, no qual realizou-se um grupo focal online no Whats $A p p$ com 17 mulheres usuárias do Instagram. Das análises, foi possível identificar que o Instagram tem se tornado um espaço no qual são investidas, de diferentes formas, estratégias que nos convocam ao consumo e à fabricação de nossos corpos e aparências.

Palavras-chave: corpo; consumo; instagram; estudos culturais; estudos de gênero.

\section{"THIS PATTERN THING IS VERY RETROGRADED”: the body as surface of countless interpretations}

\begin{abstract}
In light of Cultural Studies and Gender Studies they both in their post-structuralist strands of analysis this article gathers some research data with which we seek to dialogue in order to identify which representations are being built about body and gender concerning virtual sociability practices on Instagram social media. Methodologically it is characterized as a virtual ethnographic study in which an online focus group was conducted on Whats $A p p$ with 17 women users of Instagram. From the analyzes it was possible to identify that Instagram has become a space in which, in different ways strategies that summon us to consumption and the manufacture of our bodies and appearances are invested.
\end{abstract}

Keywords: body; consumption; instagram; cultural studies; gender studies.

\section{“ESE NEGOCIO DE ESTÁNDAR ES MUY RETRÓGRADO”: el cuerpo como superficie de innumerables interpretaciones}

Resumen

A la luz de los Estudios Culturales y los Estudios de Género, ambos en sus vertientes postestructuralistas de análisis, este artículo reúne algunos datos de investigación con los que buscamos dialogar para identificar qué representaciones se están construyendo sobre el cuerpo y el género en relación con las prácticas de sociabilidad virtual en la red social Instagram. Metodológicamente, se caracteriza como un estudio etnográfico virtual, en el que se realizó un grupo focal en línea sobre Whats $A p p$ con 17 mujeres, usuarias de Instagram. A partir de los análisis, fue posible identificar que Instagram se ha convertido en un espacio en el que, de diferentes maneras, se invierten estrategias que nos convocan al consumo y a la fabricación de nuestros cuerpos y apariencias.

Palabras clave: cuerpo; consumo; instagram; estudios culturales; estudios de género. 


\section{CONSIDERAÇÕES INICIAIS}

O corpo escolhe a si mesmo em seu conteúdo e, sobretudo, em sua forma; a anatomia deixa de ser um destino para ser uma escolha; a indústria do design espalha-se pela vida cotidiana, [...] aplicando-se ao corpo próprio. O princípio de identidade torna-se tão obsoleto quanto as formas corporais indefinidamente remanejáveis. Le Breton (2003, p. 49)

Inscrito como objeto de estudo em diversas áreas do conhecimento, o corpo tem sido tradicionalmente considerado como uma estrutura essencialmente biológica. $\mathrm{Na}$ análise cultural contemporânea, entretanto, o corpo passa a ser questionado pelo viés de que ele próprio é um construto cultural, social e histórico, dotado de sentido e significação. Se considerarmos que em cada época a atenção voltada para o corpo e os modos de nele intervir variam conforme os valores, as normas e as condutas corporais vigentes, podemos afirmar que, para além de sua materialidade orgânica, os corpos são também produzidos pela cultura. Fabricam-se em meio a múltiplas dimensões, instâncias, instituições, dispositivos e espaços de socialização que tanto ensinam, como colocam em circulação determinadas formas de se viver e conceber o corpo (GOELLNER, 2015).

À luz das perspectivas teórico-metodológicas dos Estudos Culturais e dos Estudos de Gênero, ambos em suas vertentes pós-estruturalistas de análise, neste artigo operamos com o frutífero conceito de pedagogias culturais, o qual concerne a "[...] qualquer instituição ou dispositivo cultural que, tal como a escola, esteja envolvido - em conexão com relações de poder - no processo de transmissão de atitudes e valores" (SILVA, 2000, p. 89). Busca-se, com esse enfoque, identificar e compreender a operacionalização das pedagogias culturais em múltiplos artefatos, espaços e instâncias sociais que também educam e produzem representações e identidades culturais específicas. Por representação, nos referimos aos modos como atribuímos sentidos por meio da linguagem e da cultura e, quanto à identidade, a entendemos como constituída em meio às posições de sujeito com as quais o indivíduo se identifica, investe e assume, posicionando a si mesmo como sujeito de determinados discursos (SILVA, 2003; WOODWARD, 2003).

Denise de Sant'Anna (2000) salienta a existência de uma cultura do espaço íntimo em que as imagens de embelezamento dos corpos expressam uma representação e um modelo cultural a ser seguido, conforme os interesses econômicos de cada época e, no que diz respeito ao corpo da mulher, este vem sendo alvo de inúmeros discursos, amplamente veiculados nas mídias. Visto desse modo, investigar os artefatos culturais midiáticos nos possibilita compreender as formas pelas quais os indivíduos significam e incorporam a cultura de modo pedagógico, isto é, que faz do corpo lugar de experimentações e práticas que nos comunicam algo sobre os sujeitos.

Partindo do entendimento de que pensar o corpo na contemporaneidade implica refletir para além de sua materialidade orgânica, neste artigo reunimos alguns dados de uma pesquisa maior, já finalizada, com os quais buscamos dialogar na intenção de identificar quais representações estão sendo construídas sobre corpo e gênero no que concerne à veiculação de discursos nas mídias sociais, mais especificamente no aplicativo Instagram. Para tanto, optamos pelo estudo das representações culturais pelo viés pós-estruturalista, uma vez que essa vertente busca ampliar e problematizar os pressupostos de teorias clássicas de diversas áreas do saber, deslocando a atenção da análise estruturalista dada a processos fixos de significação à compreensão de que os processos de significação - processos sociais nos quais a cultura é concebida como um campo de luta em 
DOI: $10.12957 /$ teias. $\%$ Y.50738

torno da produção de significados (SILVA, 2000) - variam de acordo com os contextos culturais e sociais em que são constituídos.

\section{ESCOLHAS METODOLÓGICAS}

A pesquisa caracteriza-se como um estudo etnográfico virtual, que consiste em uma imersão online na comunidade virtual a ser estudada. Nessa prática de pesquisa não só observamos as atividades do grupo como nos tornamos visíveis e participativas, o que nos possibilitou conhecer, de maneira implicada, as relações e as práticas envolvidas na produção de significados entre as participantes.

Christine Hine (2004), uma das pesquisadoras pioneiras nos estudos sobre as interações sociais online, propôs a Etnografia Virtual para investigações empíricas sobre os modos como a internet é utilizada e incorporada em nosso cotidiano. Hine compreende a internet a partir de duas perspectivas, a saber: como cultura e como artefato cultural. Na perspectiva da internet como cultura, os ciberespaços e as interações sociais que neles se arquitetam constituem uma cultura em si mesma, de modo que uma abordagem etnográfica possibilita a análise dos processos através dos quais os membros do grupo virtual em estudo atribuem sentidos às suas interações. Sob a ótica da internet enquanto artefato cultural, isto é, como produto da cultura, seus significados variam conforme os processos sociais de produção e uso, sendo então representada de modo distinto para cada indivíduo. Sendo assim, para uma compreensão ampla da internet, consideramos útil a contribuição da análise etnográfica em ambas as perspectivas, visto que para investigar a produção de significados nesse contexto levamos em consideração tanto as circunstâncias offline em que a internet é utilizada, quanto os espaços e as interações sociais online que emergem de seus usos.

A produção dos dados foi realizada em três etapas. Primeiramente, foi realizado um convite público no Instagram, divulgado no feed e no stories do perfil profissional da primeira autora, seguido de uma enquete para identificar as pessoas que demonstrassem interesse em participar do estudo, bem como de um link que as direcionava para a segunda etapa, que consistiu no preenchimento de um questionário elaborado e disponibilizado na plataforma Formulários Google. A terceira etapa compreendeu a criação de um grupo focal online no Whats App, que foi composto por 17 mulheres e permaneceu ativo por duas semanas, entre os meses de agosto e setembro de 2019. A escolha pelo Whats App como campo empírico de estudo ocorreu pelo entendimento de que além de ser um dos aplicativos de comunicação mais utilizados mundialmente ${ }^{1}$, ele também proporciona privacidade e segurança por meio de um protocolo de criptografia de ponta a ponta ${ }^{2}$, tanto em conversas individuais quanto em grupos.

O formato comunicacional do grupo focal contou com sessões síncronas e assíncronas de comunicação. Ou seja, as discussões ocorreram em momentos previamente determinados, permitindo que todas as interlocutoras interagissem simultaneamente ou de acordo com sua disponibilidade. As discussões foram impulsionadas através de alguns artefatos disponíveis na internet que serviram como disparadores de discussão, bem como por meio de questões levantadas pelas participantes. Tomando suas narrativas como enunciados, nos processos de análise buscamos articular os elementos discursivos ali presentes para identificar e problematizar o que vem sendo representado culturalmente sobre corpo e gênero, mais especificamente sobre o corpo da mulher e a produção de feminilidades quando articulados às práticas de sociabilidade virtual no Instagram.

\footnotetext{
${ }^{1}$ Informação retirada do Blog Oficial do Whats App, disponível em https://blog.whatsapp.com/.

${ }^{2}$ Desenvolvido para que terceiros não tenham acesso aos conteúdos compartilhados em mensagens do Whats $A p p$.
} 
Quanto à identificação das participantes, optamos por deixar a critério delas a escolha do modo como gostariam de ser mencionadas nos textos referentes à pesquisa. Foram-lhes apontadas algumas alternativas, como a escolha de um nome fictício ou por serem identificadas pelas iniciais de seus nomes, mas a maioria optou pela utilização de seus primeiros nomes. Desse modo, as identificações que aparecem no artigo tiveram seus usos previamente autorizados. Convém ainda salientar que as falas foram transcritas fidedignamente, conforme emergiram nas conversas do grupo focal, preservando-se, assim, a linguagem informal utilizada na internet.

\section{“ESSE NEGÓCIO DE PADRÃO É MUITO RETRÓGRADO”}

No intuito de fomentar as interlocuções, disponibilizamos ao grupo a versão estendida do vídeo intitulado "Dove Retratos da Real Beleza"3 (Figura 1), que serviu como disparador de discussão. Trata-se de um curta-metragem produzido em 2013 pela agência de publicidade Ogiluy \& Mather Brasil para compor parte da campanha publicitária Dove Campaign for Real Beauty, da marca de produtos de higiene pessoal Dove. No vídeo, é retratado um experimento social que reuniu algumas mulheres para que descrevessem a si mesmas enquanto, sem que elas soubessem, por trás de uma cortina, um artista forense as desenhava a partir de suas autodescrições. Posteriormente, o artista desenhou as mesmas mulheres, porém por meio da descrição de pessoas que tiveram contato prévio com elas durante o experimento.

Nos resultados, as aparências das mulheres foram representadas de formas nitidamente distintas, de modo que elas mesmas salientaram que nos desenhos realizados através das descrições de outras pessoas, suas aparências estavam mais bonitas e harmoniosas.

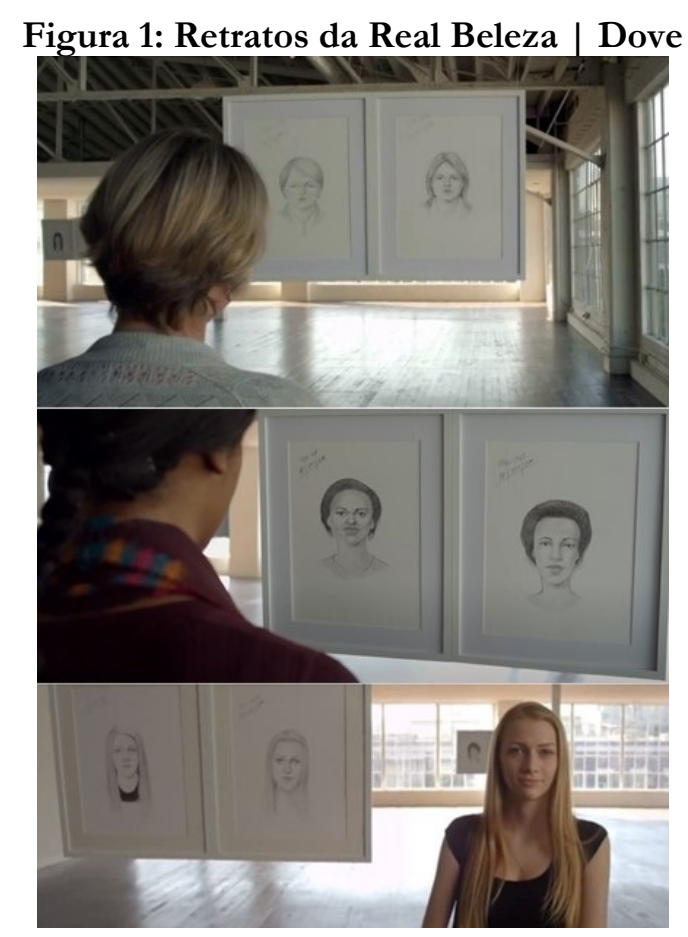

Fonte: Dove Brasil (2013), YouTube.

\footnotetext{
${ }^{3}$ Disponível em https://www.youtube.com/watch?v=I10nz0LHbcM.
} 
“Se não sou perfeita, então não sou bonita": o corpo perfeito

Ao disparar o vídeo no grupo focal, algumas participantes argumentaram haver uma tendência de buscarmos sempre a beleza e a perfeição de nossas aparências na medida em que nos deparamos cotidianamente, e especialmente através das mídias, com diversos elementos que nos instigam a mudar ou corrigir alguma imperfeição corporal:

Eu acho que nós sempre queremos mais, sempre queremos buscar a beleza e a perfeição. Nos olhamos no espelho e sempre encontramos imperfeições e algo para se mudar. Com certeza a mídia influencia ${ }^{4}$ a isso, porque as pessoas sempre estão super produzidas em filmes, novelas e até na internet, e nós nos achamos inferiores a essas pessoas por conta de toda essa beleza que na verdade é falsa, na maioria das vezes (Ana, 22).

Como podemos observar, a interlocutora menciona alguns artefatos culturais que colocam em circulação determinados corpos e estilos, funcionando como parâmetros para a construção de uma noção de beleza pessoal. Tal narrativa reforça os efeitos produzidos pela proliferação de imagens do corpo presentes nas mídias, que nos fazem imaginar e fantasiar determinadas vivências para os nossos corpos (SANTAELLA, 2008). Concordamos, entretanto, que além de produzirem efeitos em nossas experiências corporais, essas imagens também nos mobilizam subjetivamente, nos envolvem e criam desejos de cultivarmos uma bela aparência que, ao se mostrar ilusória e distante de uma suposta perfeição, produzirá efeitos negativos, tais como o sentimento de inferioridade e a consequente frustração, conforme expressa a participante ao indicar que sua aparência não contempla alguns atributos que julga como perfeitos:

Eu penso o seguinte: se não sou perfeita, então não sou bonita. Porque quem é bonito mesmo parece que tem o corpo, rosto, cabelo, tudo perfeito. Da uma frustração (Ana, 22).

E tu busca essa perfeição como? (Pesquisadora).

Não busco na verdade, só tenho vontade :-)

De mudar várias coisas

Vejo em algumas pessoas do dia a dia, algumas coisas que eu queria ter em mim e também na internet (Ana, 22).

Rosa Fischer (2006) diz não haver um espaço sequer em que não sejamos convocados/as a olhar e cuidar de nossos corpos, principalmente nos espaços midiáticos, em que

Os imperativos da beleza, da juventude e da longevidade [...] perseguem-nos quase como tortura: corpos de tantos outros e outras nos são oferecidos como modelo para que operemos sobre nosso próprio corpo para que o transformemos, para que atinjamos (ou que pelo menos desejemos muito) um modo determinado de sermos belos e belas, magros, atletas, saudáveis, eternos (p. 49-50).

Esses modelos de corpo sobre os quais a autora fala também podem ser observados na narrativa anterior, quando Ana afirma que, mesmo sem agir em seu corpo, no contato com outras pessoas, seja no cotidiano ou na internet, sente o desejo de mudar sua aparência a partir de elementos com os quais subjetivamente se identifica. Operando como um comunicador visual de

\footnotetext{
${ }^{4}$ Apesar da participante utilizar uma variação do termo influência para se referir ao poder dos discursos midiáticos, importa enfatizar que na perspectiva pós-estruturalista analisamos os efeitos produzidos pelos discursos em nossas subjetividades, uma vez que reagimos e negociamos com eles.
} 
estilos e tendências, cada corpo compõe uma virtualidade de outros corpos, representada pelo modo como conciliamos nossas aparências e afetos (LE BRETON, 2003), estes vivenciados em forma de emoções, sensações e anseios que, cuja identificação com outros corpos e aparências nos impelem a cuidar, investir e a fabricar esse que é nosso. Nesse sentido, salientando os corpos que circulam nas mídias sociais, na fala a seguir uma participante considera que a questão de padrões idealizados do corpo e da aparência tem sido mais enfatizada do que em outras épocas, associando essa ênfase às performances de influenciadores/as digitais:

Acredito que essa ideologia do corpo e da aparência ideal sempre existiu, mas acho que nos últimos anos ela vem se tornando mais presente e mais enfática na vida das pessoas, devido as Digitais Influencers, que são pessoas que vivem de sua aparência (sem ironias), que postam fotos e vídeos na cama dizendo "acabei de acordar", mas na vdd ela se preparou toda para essa aparição online, com roupa, maquiagem, cabelo, tudo feito e tudo patrocinado (Bruna, 26).

Em termos contemporâneos, influencers são pessoas que além de destacar nas mídias sociais pela exposição de pensamentos, experiências, gostos, hábitos e estilos de vida, mobilizam um grande número de seguidores/as. De acordo com Raquel Recuero, em entrevista cedida a Brambilla e Glette (2017), esses sujeitos ocupam posições privilegiadas na rede e, por meio de estratégias publicitárias específicas, são capazes de influenciar e conduzir a determinadas preferências e decisões de consumo. Cabe dizer que não se trata, contudo, de condutas irrefletidas por parte dos/as consumidores/as, mas que se exercem por meio de processos subjetivos gerados a partir de um vínculo muito mais afetivo do que impessoal. Por intermédio de uma comunicação informal e amistosa, a relação entre influencers e seus/suas seguidores/as assume particularidades de proximidade, amizade e confiança, tornando mais eficaz a criação de desejos, nestes últimos, de consumir e fazer uso dos mesmos produtos e serviços utilizados pelos/as influenciadores/as.

Identificando o poder dessa relação, diversas empresas veem, nos/as influenciadores/as e em seus canais de comunicação, meios potentes para investir na publicidade de suas marcas. No Instagram, os perfis de influenciadoras digitais voltados para os ramos da moda e da beleza, por exemplo, evidenciam o empenho em disponibilizar ao público com o qual dialogam, fotos e vídeos selfie com dicas, testes, relatos de intervenções cirúrgicas e estéticas, técnicas e tutoriais de maquiagens, penteados, vestuário e acessórios, aproveitando a deixa para divulgar as novidades das marcas que representam. Sobre isso, uma participante relata o seguinte:

Eu sigo vários perfis do Instagram de moda e beleza. Tem me chamado bastante a atenção pra mulheres bem novas e que eu considero que se encaixam no padrão de beleza da sociedade fazendo procedimentos estéticos. A venda por cosméticos tá bem forte tbm. Cada dia um produto novo que promete nos deixar mais bonitas, mais jovens. (Laís, 31).

Nota-se, nessa narrativa, que as estratégias de produção de conteúdo e de endereçamento utilizadas por influenciadoras de moda e beleza denotam o intuito de promover, experimentar e disseminar maneiras de manter uma bela aparência. No entanto, essa manutenção implica em investimentos que cada sujeito é instigado a exercer sobre si. A beleza como construção diária, fruto de uma dedicação à qual cada mulher deve exercer sobre si mesma, só foi assim considerada em meados do século XX, quando, segundo Sant'Anna (2003), a cosmética se emancipa como ciência, tornando-se independente da química e da dermatologia. A partir disso, as práticas de embelezamento deixaram de ser apenas aceitas e passaram a se tornar um direito de toda mulher, porém 
[...] quanto mais a beleza é considerada um direito inalienável de toda mulher, mais sua conquista e sua definição se tornam complexas, incluindo uma panóplia crescente de produtos e de serviços voltados aos cuidados corporais. Mas, ao mesmo tempo, quanto mais ela se torna um direito, menos autoritário deve ser o apelo publicitário para a sua valorização (p. 149).

Nesse sentido, torna-se possível problematizar o modo como se efetivam as performances de influenciadores/as digitais. Ao se disporem, e também seus corpos, a experimentações dos mais variados tipos de produtos, procedimentos e serviços, operam com estratégias muito mais voltadas para uma apreciação despretensiosa do que à demonstração explícita de que se trata de um anúncio publicitário. Ainda que se tenha o objetivo de promover as marcas que representam, essas performances adquirem um quê de informalidade, pois utilizam-se, muitas vezes, de uma linguagem sutil, discreta e dialógica, afeiçoada à sua audiência. Talvez por isso sejam tão eficazes quanto os anúncios que explicitamente incutem a ideia de necessitarmos um certo produto. Assim, a linguagem, o contexto e a relação com os/as seguidores/as parecem ser mais representativos de um pretexto do que de um apelo para o consumo.

Ao salientar a aparência jovem como uma característica investida por anúncios publicitários de cosméticos, a interlocutora Laís endossa a reflexão de Nádia de Sousa (2016), que chama atenção para a noção de uma eterna juventude promovida pelas mídias, especialmente ao veicularem um mercado que, além de ser atrativo, vale-se do prazer e do consumo como princípios de "gratificação imediata". A juventude assume, nessa perspectiva, características menos ligadas a uma etapa de vida definida pela idade, e mais voltadas para um estilo de vida ou para um arquétipo cultural. Nessa direção, o enfoque dado às juventudes contemporâneas privilegia uma posição de sujeito consumidor, favorecendo a produção de uma cultura e de um perfil de consumo que viabiliza uma identificação com a figura de uma juventude hedonista, livre e sensual, um modelo ideal de beleza e liberdade a ser conquistado por todos/as (KEHL, 2004).

Resgatando brevemente a problemática de uma representação que associa beleza à perfeição, apresentada no início dessa discussão, em resposta à narrativa de Ana, outra participante relativiza essas noções, sugerindo que os significados sobre "ser belo/a" e "ser perfeito/a" variam tanto de pessoa para pessoa, como coletivamente, pois "[...] cada sociedade tem uma cultura, vamos dizer assim, da beleza perfeita" (Graziela, 27). Dirigindo-se à Ana, a interlocutora continua:

Então, Ana. Com isso a gente fica, assim, desesperada buscando sempre aquilo. Só que aquilo pode ser bonito, pode ser perfeito, para aquela pessoa. E em mim, e em você, não fica bom, não fica perfeito, vamos dizer assim. Porque quanto mais o ser humano tenta buscar o perfeito, ele nunca vai achar. Vai ser uma busca incessante [áudio transcrito] (Graziela, 27).

Entendendo as noções de beleza e perfeição como construções culturais plurais, isto é, não naturais e universais, mas fabricadas pelas representações de corpo que cada cultura institui como adequadas, é importante pensar e problematizar as representações daqueles corpos que escapam à norma, pois além de expressarem uma diferença, esses corpos são marcados, principalmente, por desigualdades (GOELLNER, 2010).

Essas desigualdades foram discutidas pelas participantes do grupo focal e merecem especial atenção, pois suas narrativas denunciam o modo como alguns discursos criam e reiteram representações qualitativamente desproporcionais sobre o corpo, sobretudo quando determinados atributos físicos e estéticos são associados a fatores como os de saúde e doença, conforme apresentamos nas próximas discussões. 
"O corpo gordo ainda é o que mais sofre": o corpo estigmatizado

Quando discutíamos sobre a estética corporal, uma das participantes levantou a pauta sobre a obesidade, questionando se esta poderia ser considerada como uma doença ou se estaria mais relacionada a aspectos atinentes à autoestima. $\mathrm{Na}$ discussão emergiram questões que salientaram representações sobre a aparência do corpo a partir de dois extremos opostos: o excesso de gordura corporal e a magreza extrema. Diferentes significados foram atribuídos, sobressaindo-se a ideia de que a obesidade leva ao adoecimento psíquico, em especial no que se refere à aceitação do próprio corpo, enfatizada como condição importante para o não adoecimento:

Vocês acham que obesidade é uma doença ou autoestima?

É uma porta para várias doenças, principalmente para depressão. Às vezes a autoaceitação influencia para melhora de tais problemas que a obesidade pode desencadear. Principalmente mental (Janaína, 24).

Eu acho que a obesidade é muito tratada como doença mas acho que grande parte disso é uma doença da sociedade também, pq tem muito gordo mais saudável que muita gente magrela, eu trabalho na área de saúde e as vezes, aquela pessoa magra, nos "padrões" tá com a saúde muito pior que a minha, por exemplo. Eu acho que tanto o gordo quanto o magro não precisam se encaixar em padrões desde que mantenham a saúde em dia (Délis, 25).

Sim!!! Pessoa com problemas e transtornos alimentares não podem ser consideradas saudáveis por estarem nos padrõezinhos. Como vc disse peso não é sinônimo de saúde né (Lívia, 26).

Mas psicologicamente, se a pessoa não se aceitar, vira doença pela forma que ela espera e imagina que as pessoas a enxergam quando na verdade, é como ela enxerga a si mesma (Délis, 25).

$\mathrm{Na}$ perspectiva das interlocutoras, a obesidade em si não é vista como desencadeadora do adoecimento psíquico, mas o modo como ela é percebida e tratada socialmente. A aceitação do próprio corpo é uma questão bastante enfatizada, ficando evidente a noção de não se tratar apenas de uma autoaceitação, mas principalmente da aceitação social, marcada pelo olhar discriminador de quem vê o corpo:

Eu acho que o corpo gordo ainda é o que mais sofre. Nesta perspectiva estética e de auto aceitação a partir da aceitação do outro, sabe. A perspectiva social da obesidade é muito estigmatizada. O corpo gordo é totalmente vinculado a uma imagem de descuido, desleixo. Não se tem socialmente a imagem "Ah a pessoa está doente", tem-se a imagem de "pessoa é desleixada" (Angélica, 28).

Nessa fala, problematizam-se as representações sobre o corpo gordo como uma falta de cuidados, salientando fundamentalmente o modo como esses corpos são julgados e classificados pelos olhares alheios. Os discursos da saúde, tanto quanto os do corpo perfeito e do bem-estar, implicam em uma concepção de que as doenças e os corpos que fogem do padrão culturalmente idealizado representam um fracasso ou uma falha pessoal. Tal perspectiva sustenta a visão de Francisco Ortega (2008) que, ao falar especificamente sobre os domínios da feminilidade, demonstra que o corpo supostamente desenquadrado das normas hegemônicas de saúde e boa forma denota, consequentemente, uma representação de atitudes de uma mulher negligente que não exerce controle, nem vigia a si mesma. Os estereótipos do corpo ideal causam efeitos estigmatizadores e excludentes, assim como vão configurando as identidades responsáveis e as 
desviantes. Além de aumentarem os preconceitos, esses estereótipos contribuem negativamente no processo de tornar ainda mais complexo o enfrentamento de não se conseguir atingir esse ideal.

No sentido oposto, em que a magreza extrema foi levada à discussão, Lívia relata uma experiência pessoal de emagrecimento involuntário causado por uma doença. Délis complementa esse assunto com a história de um quadro de anorexia vivenciado por uma influenciadora digital norte-americana. Em ambos os casos, pode-se problematizar o modo como o corpo e a beleza têm ocupado uma posição anteposta à saúde, conforme aponta o diálogo a seguir:

Eu sempre fui magra e há uns 3 anos eu perdi $10 \mathrm{~kg}$, eu tava pesando $45 \mathrm{~kg}$. Eu tava doente e recebia vários elogios. E eu falava que eu tava doente qnd falavam que eu tava bonita. Escutei que eu era grossa e mal educada (Lívia, 26).

Sim, teve há uns anos atrás, uma americana que estava anoréxica e estava com seu peso mas ela foi mantendo pq ela não notava que estava doente e as pessoas na rede social dela sempre elogiavam o corpo dela, na época eu li a notícia e tinham fotos do perfil dela, você via nitidamente os ossos sendo contornados pela pouca musculatura e pele, ainda sim, a rede social a idolatrava por estar tão magra. Muitos invejavam aquele corpo (Délis, 25).

A partir destes e dos demais relatos apresentados nessa discussão, vemos que tanto a magreza extrema como o excesso de gordura corporal não são tratados como doenças, mas também não são vistos da mesma forma. Enquanto o corpo obeso é associado a desleixo e falta de cuidados, o corpo excessivamente magro é salientado como atributo de beleza, ainda que seja visível o seu adoecimento. Embora a produção histórico-discursiva sobre o corpo o evidencie em seu caráter de invenção, os regimes de verdade contemporâneos se mostram imbuídos em uma cultura somática, isto é, o corpo ainda é concebido em relação à sua materialidade mais exordial volume, forma e superfície (CÉSAR, 2009). Apesar de não ter deixado de ser alvo de estratégias de vigilância, controle e de produção subjetiva, o corpo contemporâneo é mais "plástico e maleável", como demonstram os inúmeros procedimentos aos quais é submetido.

“Eu não sou uma Barbie, eu sou uma pessoa real": o corpo plástico

Dentre as várias intervenções e modificações corporais pelas quais se recorre almejando a melhoria do corpo e da aparência, a cirurgia plástica foi mencionada por uma das interlocutoras, ao referir que na época da pesquisa estava prestes a fazer dois procedimentos cirúrgicos:

Eu tenho vontade de mudar bastante meu corpo

Vou fazer uma cirurgia plástica em outubro

Pode ser que seja pelo que eu consumo

Mas depois de duas gravidez o meu corpo mudou bastante

E eu já vi que sozinha não consigo mudar o que me incomoda (Laís, 31).

Que cirurgia tu vais fazer? (Pesquisadora).

Eu vou fazer mastopexia (pra levantar os seios) e cirurgia no abdômen pra retirar as estrias da barriga (Laís, 31).

Nesta narrativa, é possível problematizar alguns aspectos, dentre os quais destaca-se a possibilidade de que suas motivações para a realização dos procedimentos estejam atreladas às suas especificidades individuais de consumo, às mudanças corporais decorrentes de duas gestações, e à dificuldade de alcançar, por conta própria, os resultados que deseja. Entendemos que consoante a lógica do consumo, irrompem diferentes hábitos e comportamentos nos domínios da aparência corporal, sobre a qual cada sujeito se torna responsável pelo gerenciamento na iminência de obter 
resultados eficazes e imediatos. Entretanto, essa responsabilidade vem acompanhada de discursos que ressaltam a autonomia e a liberdade de escolha para agir no corpo e, como tal, cada pessoa encontra-se sujeita a ser avaliada por meio do corpo e da saúde que apresenta. Por isso é preciso ter pressa, já que tem se tornado "[...] urgente eliminar toda e qualquer insatisfação física e mental, acabar com uma real ou suposta imperfeição, corrigir cada detalhe, construir a forma considerada mais adequada [...]" (COUTO, 2009, p. 42).

Tal entendimento se torna ainda mais evidente quando, em narrativa, uma participante jovem, com 31 anos e recentemente mãe, se mostra insatisfeita com o seu corpo, atribuindo as mudanças corporais às suas duas gestações. E ao perceber que sozinha não dará conta de mudar o que lhe incomoda, recorrerá à cirurgia plástica para corrigir erros e imperfeições para ficar com o corpo mais próximo do padrão que deseja e que também circula em diversos espaços educativos, tais como a publicidade, a propaganda e as mídias sociais, como ela enfatiza no foco desse estudo.

É também nesse sentido que a decisão pelas intervenções implica uma prática reflexiva de escolha, não apenas pelo alto custo do investimento, mas também pelo receio de qualquer consequência negativa que possa ser ocasionada pelos procedimentos, conforme evidencia a seguir:

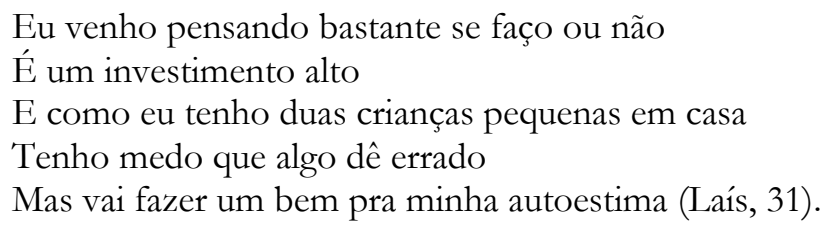

Desejo e medo não são alheios à história das transformações corporais em prol do embelezamento e, como pudemos perceber, a reflexividade sobre a escolha de realizar intervenções estéticas denota um dilema que está além do desejo e do risco, pois também carrega aspectos subjetivos, financeiros, maternais e familiares, abrangendo a vida pessoal como um todo. Além disso, é característico da vida contemporânea a familiaridade com a incerteza e com a provisoriedade da escolha, já que as metamorfoses corporais passaram a ser a norma e, sendo assim, cada indivíduo se deseja livre em sua autoconstrução (COUTO, 2009; SANT'ANNA, 2003).

Outro aspecto da fala supracitada que merece atenção é a decisão de realizar as cirurgias atrelada à melhoria da autoestima. Com efeito, a cultura visual contemporânea fortalece uma atenção profunda sobre o corpo, voltada sobretudo aos discursos do prazer e do bem-estar, que nutrem, instigam e nos movem a práticas de consumo em busca da excelência corporal. $\mathrm{O}$ antropólogo francês David Le Breton (2003) analisou o corpo como acessório do sujeito e artefato estético da presença, indicando que a vivência corporal implica uma encenação de si que estimula o desejo de uma reapropriação da existência do corpo. Este, por sua vez, torna-se o território de uma identidade provisória e manejável, mediante a qual nos (re)afirmamos a todo instante investindo e modificando o nosso corpo, seja para atualizá-lo, torná-lo completo ou para transformá-lo conforme a idealização que sobre ele operamos.

Pode-se considerar, nesse contexto, que a identidade é tão fluida quanto a crescente multiplicação de técnicas, serviços e produtos das mais diversas ordens e variações que visam complementar ou aperfeiçoar a estética corporal. Amplamente divulgados e cada vez mais acessíveis a nós, esses artefatos estão disponíveis, em diversos espaços, para dialogar com nossos desejos e se ajustarem às nossas necessidades, independente das nossas distintas posições socioeconômicas (BECK, HENNING, VIEIRA, 2014). Além da variabilidade de produtos, na discussão do grupo focal são mencionados, como formas de complementação estética, os produtos com fins estéticos que têm uma vida útil definida, como salienta Bruna (26): "[...] O que vejo aqui 
onde moro é a febre das *Sobrancelhas micropigmentadas*, *unhas gel* e cílios que duram 15 dias, mas eu penso 'gente, eu não sou uma Barbie, eu sou uma pessoa real!"'. Cada vez menos duráveis, esses acessórios demonstram que a valorização da aparência corporal e os modos contemporâneos de nela intervir associam-se a uma fértil aplicabilidade mercadológica, sobretudo quando corpo e beleza se tornam uma mega-indústria em potencial. Dentre outros aspectos, essas características de consumo assim se configuram porque

\begin{abstract}
Vivemos sobre um presenteísmo onde as formas recém-adquiridas são imediatamente superadas para dar lugar a outras que também não podem permanecer. É próprio do consumo o fato de que tudo deve ser rapidamente descartado, tudo no corpo, suas formas, seus fragmentos e próteses, naturais e artificiais, também precisam ser, incessantemente, substituídas. Nos tempos atuais existe uma febre de brevidades que faz com que tudo no corpo tenha um prazo de validade cada vez menor. Para que o corpo possa durar eternamente é preciso que não cesse de ser reciclado e turbinado. As peças com prazos vencidos exigem a substituição voraz. Todas as peças e formas são provisórias, o que intensifica o seu aspecto comercial (COUTO, 2009, p. 51).
\end{abstract}

Desse modo, o mercado da estética corporal muito se vale dos desígnios de consumo postos nas sociedades contemporâneas. A avidez e a pressa marcam a vida das pessoas, instigam o desejo de não ficar para trás, de não se mostrar desleixado/a com o corpo, de investir no que é de fato seu, já que em um universo marcado pela liquidez das relações, o que temos é ele: o corpo. Como então não cuidá-lo, não pavoneá-lo, não torná-lo produtivo, eficaz e belo mediante os desígnios postos pelo consumo?

\title{
"Forte como uma garota": o corpo empoderado
}

Em nossas discussões anteriores, problematizamos as formas pelas quais o consumo vem operando sobre nossas condutas, tornando-se um dos principais norteadores de nossos modos de agir e de nos posicionarmos no mundo. Em vias de finalizar este artigo, a seguir versamos sobre como os corpos femininos e as feminilidades vêm sendo representados em enunciados que visam desconstruir as representações que posicionam a mulher como sujeito do "sexo frágil". Para isso, retomamos a questão da estética através da marca Salon Line, mencionada por Graziela, que traz à discussão um contraponto à visão de que padrões de beleza feminina ainda sejam preservados e incentivados em alguns anúncios publicitários.

$\mathrm{Na}$ narrativa a seguir, a participante demonstra que contemporaneamente existe um outro movimento feito pela publicidade, qual seja, o de fazer com que as mulheres se aceitem como são por meio de discursos que promovem a valorização da beleza autêntica e natural da mulher:

Bom, apesar que agora a gente consegue ver que os anunciados estão mudando, né, de certa forma. Estão valorizando mais a beleza natural feminina, né. Porém são poucos cosméticos que estão fazendo isso. Graças ao movimento feminino, esse "padrão" tem sido rompido aos poucos. Você pode observar a salon line; cria produtos para as mulheres assumir o cabelo do jeito que é... (natural). Tenta "combater" o padrão do cabelo liso. Esse negócio de padrão, é muito retrógrado (Graziela, 27).

Ao acessar o perfil da Salon Line no Instagram, foi possível perceber diversas estratégias de engajamento e marketing utilizadas pela marca, dentre as quais destacam-se ilustrações de estereótipos que subvertem as normas de fragilidade e sensibilidade que por muito tempo foram 
DOI: $10.12957 /$ teias.\%Y.50738

atribuídas à mulher. Como pode ser observado nos enunciados da Figura 2, a marca se utiliza de elementos visuais e textuais em vias de enfatizar a força da mulher. 
DOI: $10.12957 /$ teias.\%Y.50738

Figura 2: Posts da Salon Line no Instagram e a representação de força atribuída à mulher

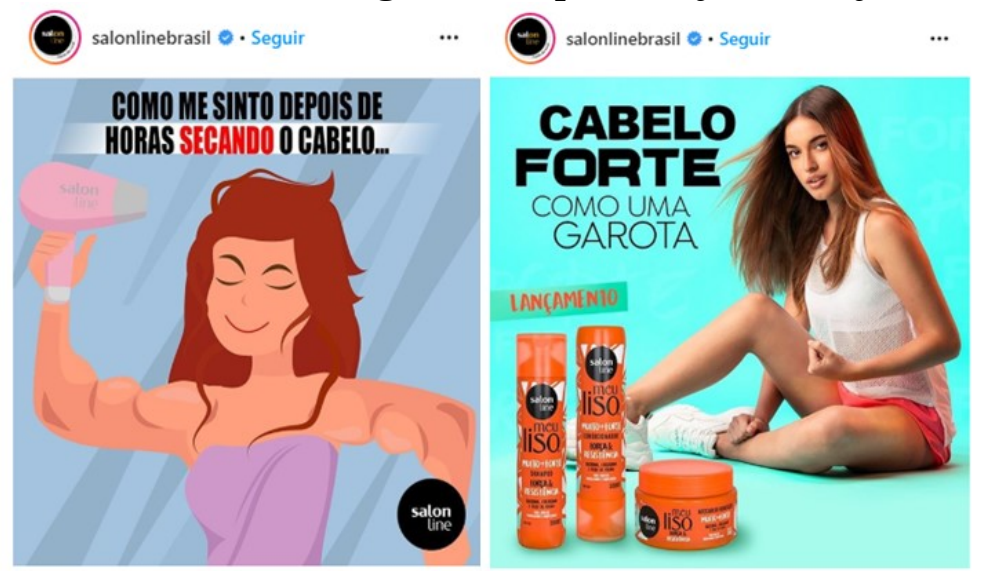

Fonte: Instagram@salonlinebrasil, 2020

Nas práticas contemporâneas de consumo, há uma convocação ao engajamento social e político que se concretiza na identificação e no uso de determinadas marcas e produtos. Ao utilizarmos esses artefatos, que funcionam como marcadores identitários, demonstramos nosso posicionamento diante de discursos que as marcas defendem ou visam combater. Sendo assim, não consumimos apenas uma mercadoria, mas sobretudo comportamentos e experiências que denotam pertencimentos a grupos sociais distintos. Expressamos, por intermédio de nossas aquisições e no uso desses artefatos, nosso engajamento com campanhas e causas coletivas (BECK, HENNING \& VIEIRA, 2014).

Nos enunciados da Salon Line, tanto a presença de uma figura que ilustra a força da mulher quanto a expressão "forte como uma garota" podem ser problematizadas a partir da perspectiva de Ruth Sabat (2001). Esta autora analisou quão potentes são os anúncios publicitários em nos mostrar - e ensinar - como as relações de gênero vêm sendo determinadas em nossas sociedades, isto é, as formas como são atribuídos às mulheres e aos homens, significados sobre as condutas socialmente desejáveis que cada um/a deve assumir enquanto sujeito feminino ou masculino. Apesar do caráter normativo de alguns discursos publicitários, estes também se ocupam em subverter alguns padrões já estabelecidos através da ênfase nas diferenças. Contudo, nem sempre essa subversão opera em vias de contestar os padrões hegemônicos e valorizar as diferenças, mas de chamar atenção para determinada marca ou produto de consumo que contemple uma gama maior de sujeitos, vistos sempre como consumidores em potencial.

Ainda que salientar as diferenças seja uma estratégia intencional para atingir, seduzir e capturar o máximo possível de consumidores/as, ao reforçar os discursos que já circulam socialmente sobre as diferenças, visando promover identificações diversificadas, a publicidade está não somente, mas simultaneamente, as reproduzindo. Logo, coloca-se em suspeição a autonomia dos discursos publicitários, pois "[...] quando a publicidade fala, também nós estamos falando" (SABAT, 2001, p. 14). Nesse sentido, parece que a problemática da publicidade reside no ato de reforçar não só as diferenças, mas também as desigualdades, prescrevendo distintamente condutas, cuidados e investimentos que supostamente seriam mais apropriados para cada gênero. E como vimos nas discussões, há um deslocamento discursivo em alguns anúncios publicitários, pois agora, mais do que nunca, além de belas, somos também instigadas a exibir nossa força e capacidade de resistência. Produzem-se, assim, outros estereótipos de feminilidade. 


\section{ALGUMAS CONSIDERAÇÕES}

Em face do que discutimos neste artigo, mostra-se oportuno o exercício de uma leitura atenta e crítica de enunciados que circulam nas mídias sociais, seja em sua forma visual, textual ou verbal, como aqueles que aparecem nas narrativas de influenciadores/as digitais, estrategicamente produzidos e pensados para criar desejos e práticas de consumo que instigam a manutenção, o controle e o aperfeiçoamento de nossos corpos para que se enquadrem em parâmetros considerados como ideais. Ao nos atentarmos às representações difundidas nesses meios torna-se possível problematizar as mídias sociais como espaços de negociação e produção de significados.

Como um desses espaços, o Instagram tem se tornado um lugar privilegiado, em que diversas marcas e empresas investem, de diferentes formas, para nos convocar ao consumo e a fabricarmos nossos corpos. Utilizam-se, para tal, de técnicas e estratégias que se ocupam em produzir e ensinar valores, condutas, hábitos e modos de ser implicados no corpo, demonstrando, assim, o funcionamento de determinadas pedagogias culturais. As discussões realizadas nessa pesquisa evidenciam diversas formas através das quais os corpos femininos vêm sendo educados em meio a diferentes discursos - econômicos, culturais, sociais, de saúde e bem-estar - que circulam no Instagram. Incutidos pela lógica do prazer atrelada ao consumo, esses discursos integram, reproduzem e fabricam outras representações culturais sobre o corpo, sinalizando suas inúmeras possibilidades de interpretação.

Mostram-se potentes para os campos da Educação e dos Estudos Culturais, discussões que visam problematizar as práticas discursivas e não-discursivas empreendidas e amplamente difundidas no Instagram, bem como nas demais mídias sociais da internet. Principalmente porque nos interpelam em meios de comunicação geralmente utilizados em momentos de lazer, e que também têm se mostrado atraentes campos de investimentos e negociações paro o consumo. Mostra-se igualmente importante refletirmos sobre a relevância de nos distanciarmos de tudo aquilo com o que nos familiarizamos e naturalizamos mediante a interiorização de determinados discursos. Problematizar o próprio pensamento é um exercício fundamental para compreendermos como nos identificamos e nos implicamos com algumas representações por meio de processos subjetivos que nos constituem tão profundamente.

\section{REFERÊNCIAS}

BECK, Dinah; HENNING, Paula; VIEIRA, Virgínia. Consumo e cultura: modos de ser e viver a contemporaneidade. Educação, Sociedade \& Culturas, n. 42, p. 87-109, 2014. Disponível em https://www.fpce.up.pt/ciie/sites/default/files/ESC42 08DinahBeck.pdf. Acesso em 23 abr. 2020.

BRAMBILLA, Ana; GLETTE, Gabriela. Influenciadores e campo social: entrevista com Raquel Recuero. Revista Communicare, v. 17, edição especial, p. 38-42, 2017. Disponível em https://casperlibero.edu.br/wp-content/uploads/2017/09/3-Entrevista-Communicare-17Edi\%C3\%A7\%C3\%A3o-Especial.pdf. Acesso em 14 abr. 2020.

CÉSAR, Maria Rita. (Des)educando corpos: volumes, comidas, desejos e a nova pedagogia alimentar. In: RAGO, Margareth; VEIGA-NETO, Alfredo (orgs.). Para uma vida não-fascista. Belo Horizonte: Autêntica Editora, 2009. 269-279.

COUTO, Edvaldo. Uma estética para corpos mutantes. In: COUTO, Edvaldo; GOELLNER, Silvana (orgs.). Corpos Mutantes: ensaios sobre novas (d)eficiências corporais. Porto Alegre: Editora da UFRGS, 2009. p. 41-54. 
DOI: $10.12957 /$ teias. $\%$ Y.50738

FISCHER, Rosa Maria. Televisão \& Educação: fruir e pensar a TV. Belo Horizonte: Autêntica, 2006.

GOELLNER, Silvana. A educação dos corpos, dos gêneros e das sexualidades e o reconhecimento da diferença. Cadernos de Formação RBCE, v. 1, n. 2, p. 71-83, mar. 2010. Disponível em http://revista.cbce.org.br/index.php/cadernos/article/view/984. Acesso em 17 abr. 2020.

GOELLNER, Silvana. Corpo: (re)pensando entendimentos, articulações e possibilidades. Diversidade e Educação, v. 3, n. 5, p. 4-9, jan./jun, 2015. Disponível em https://periodicos.furg.br/divedu/article/view/6361. Acesso em 23 abr. 2020.

HINE, Christine. Etnografia virtual. Trad. Cristian P. Hormazábal. Barcelona: Editora UOC, 2004.

KEHL, Maria Rita. A juventude como sintoma da cultura. In: NOVAES, Regina; VANNUCHI, Paulo (orgs.). Jwventude e sociedade: trabalho, educação, cultura e participação. São Paulo: Perseu Abramo, 2004. p. 89-114.

LE BRETON, David. Adeus ao corpo: antropologia e sociedade. Campinas: Papirus, 2003.

ORTEGA, Francisco. O corpo incerto: corporeidade, tecnologias médicas e cultura contemporânea. Rio de Janeiro: Garamond, 2008.

SABAT, Ruth. Pedagogia cultural, gênero e sexualidade. Rev. Estud. Fem., Florianópolis, v. 9, n. 1, p. 9-21, 2001. Disponível em https://doi.org/10.1590/S0104-026X2001000100002. Acesso em 24 abr. 2020.

SANT'ANNA, Denise de. Descobrir o corpo: uma história sem fim. Educação \& Realidade, v. 25, n. $2, \quad$ p. 49-58, jul./dez. 2000. Disponível em https://seer.ufrgs.br/educacaoerealidade/article/view/46832. Acesso em 23 abr. 2020.

SANT'ANNA, Denise de. Corpo e embelezamento feminino no Brasil. Iberoamericana, v. 3, n. 10, p. 143-151, 2003. Disponível em https://doi.org/10.18441/ibam.3.2003.10.143-151. Acesso em 14 abr. 2020.

SANTAELLA, Lucia. Artes do corpo biocibernético e suas manifestações no Brasil. Nuestra América, Porto, n. 5, p. 147-163, jan./jul. 2008. Disponível em http://hdl.handle.net/10284/2643. Acesso em 14 abr. 2020.

SILVA, Tomaz Tadeu da. Teoria cultural e educação: um vocabulário crítico. Belo Horizonte: Autêntica Editora, 2000.

SILVA, Tomaz Tadeu da. A produção social da identidade e da diferença. In: SILVA, Tomaz Tadeu da (org.). Identidade e diferença: a perspectiva dos Estudos Culturais. Petrópolis: Vozes, 2003. 73-102.

SOUSA, Nádia de. Culturas juvenis: formas de "ser/estar com", indicadoras de socialidades na contemporaneidade. Cadernos de Pesquisa: Pensamento Educacional, v. 11, n. 29, p. 31-30, set./dez. 2016. Disponível em https://seer.utp.br/index.php/a/article/view/451. Acesso em 14 abr. 2020.

WOODWARD, Kathryn. Identidade e diferença: uma introdução teórica e conceitual. In: SILVA, Tomaz Tadeu da (org.). Identidade e diferença: a perspectiva dos Estudos Culturais. Petrópolis: Vozes, 2003. 7-72. 


\section{Informações das autoras}

Julia da Fonseca Lopes

Universidade Federal do Rio Grande - FURG

E-mail: ju.flopes@hotmail.com

ORCID: http://orcid.org/0000-0001-9219-0929

Link Lattes: http://lattes.cnpq.br/ 7762532338392479

Dinah Quesada Beck

Universidade Federal do Rio Grande - FURG

E-mail:dinahqbeck@gmail.com

ORCID: http://orcid.org/0000-0003-3519-2244

Link Lattes: http://lattes.cnpq.br/3666634283647501 